\title{
Article
}

Arq Neuropsiquiatr 2010;68(1):98-102

\section{Central nervous system abnormalities in patients with oculo-auriculo-vertebral spectrum (Goldenhar syndrome)}

\author{
Rafael Fabiano Machado Rosa ${ }^{1,2}$, Carla Graziadio' ${ }^{\text {, Rene Lenhardt³ }}$ \\ Ronnie Peterson Marcondes Alves ${ }^{3}$, Giorgio Adriano Paskulin ${ }^{1,2}$, \\ Paulo Ricardo Gazzola Zen ${ }^{1,2}$
}

\begin{abstract}
Objective: To describe the central nervous system (CNS) alterations present in a sample of oculo-auriculo-vertebral spectrum (OAVS) patients, trying to correlate them with other clinical features. Method: Seventeen patients with diagnosis of OAVS were evaluated. All presented radiological evaluation of the CNS, normal GTG-Banding karyotype and clinical features involving at least two from the four following areas: oro-cranio-facial, ocular, auricular and vertebral. Results: CNS alterations were verified in eight from seventeen patients (47\%). Diffuse cerebral hypoplasia, dilated lateral cerebral ventricles (asymptomatic hydrocephalus), corpus callosum dysgenesis and frontal hypodensities were the most frequent abnormalities. Presence of ophthalmologic abnormalities was the only clinical association observed, being significantly more frequent among patients with cerebral alterations (63\% versus 11\%). Conclusion: CNS abnormalities are frequent in patients with OAVS, especially in carriers of ophthalmologic alterations. However, the absence of detectable cerebral abnormalities did not exclude the possibility that these subjects will subsequently present neurological symptoms.
\end{abstract}

Key words: Goldenhar syndrome, facial asymmetry, central nervous system, eye abnormalities.

Anormalidades do sistema nervoso central em pacientes com espectro óculo-aurículovertebral (síndrome de Goldenhar)

\section{RESUMO}

Objetivo: Descrever as alterações do sistema nervoso central (SNC) presentes em uma amostra de pacientes com espectro óculo-aurículo-vertebral (EOAV), tentando correlacioná-las com os demais achados clínicos. Método: Foram avaliados dezessete pacientes com diagnóstico de EOAV. Todos apresentavam avaliação radiológica do SNC, cariótipo por bandas GTG normal e achados clínicos em pelo menos duas das quatro das seguintes áreas: oro-crânio-facial, ocular, auricular e vertebral. Resultados: Alterações do SNC foram verificadas em oito dos dezessete pacientes (47\%). Hipoplasia cerebral difusa, dilatação dos ventrículos cerebrais laterais (hidrocefalia assintomática), disgenesia do corpo caloso e hipondesidades frontais foram as anormalidades mais frequentes. A presença de anormalidades oftalmológicas foi a única associação clínica observada, sendo significativamente mais comum entre pacientes com alterações cerebrais (63\% versus 11\%). Conclusão: Anormalidades do SNC são frequentes entre pacientes com EOAV, especialmente em portadores de alterações oftalmológicas. Entretanto, a ausência de anormalidades cerebrais detectáveis não exclui a possibilidade de que estes indivíduos venham subseqüentemente a apresentar sintomas neurológicos.

Palavras-chave: síndrome de Goldenhar, assimetria facial, sistema nervoso central, anormalidades do olho. 
Oculo-auriculo-vertebral spectrum (OAVS) (OMIM $164210)^{1}$ is a heterogeneous and relatively common condition. Also known as Goldenhar syndrome and hemifacial microsomia, is observed in around 1 per 5,600 live births. Familial history suggesting an autosomal recessive and dominant pattern of inheritance has been reported. However, the majority of the OAVS cases are sporadic and without a known etiology $y^{2-4}$. The clinical features are characterized by anomalies, usually asymmetric, involving structures originated from the first branchial archs, ie face, eyes, ears and spine.

Cerebral alterations have been frequently described and associated with the presence of specific features and severity of the clinical presentation ${ }^{2,4-8}$.

Thus, the objective of our study was to describe the central nervous system (CNS) abnormalities present in a sample of OAVS patients, trying to correlate these alterations with other clinical features.

\section{METHOD}

We retrospectively evaluated seventeen OAVS patients, attended in a period of 30 years by the Serviço de Genética Clínica da Universidade Federal de Ciências da Saúde de Porto Alegre/Complexo Hospitalar Santa Casa de Porto Alegre, Rio Grande do Sul, Brazil. These were selected from the total sample of OAVS patients $(n=34)$ due to the presence of radiological evaluation of the CNS through computadorized tomography (CT) scan and/or magnetic resonance imaging (MRI). Moreover, the selected patients presented clinical features involving at least two from the four main areas that belong to the phenotypic spectrum of the syndrome (oro-cranio-facial, ocular, auricular and vertebral $)^{4}$ and normal chromosomal study through GTG-Banding karyotype. It was performed a data collection including sex, age at first evalu- ation, anthropometric measures, and findings of the clinical examination, complementary evaluations and clinical evolution. Their anthropometric measures were evaluated through standard growth charts9. Patients who started to walk without support only after 18 months of age were considered with neuropsychomotor delay ${ }^{6}$. Facial microsomia and microtia localization was used as reference to determine the side of the syndrome commitment (right, left or bilateral), in agreement with the criteria adopted by Rollnick et al. ${ }^{10}$.

Fisher exact test was used for statistical comparison of our data with the literature, as well as between the frequencies found in the groups with and without CNS abnormalities of our sample, considering $\mathrm{p}<0.05$ values as significant.

Thus, from the seventeen patients, twelve were male and five female, with age at first evaluation ranging from 1 day of life to 17 years (median of 1 month and 23 days). Eleven patients came from pediatrics and six from other specialties (only one by neurology). Two patients had clinical features involving the 4 areas that belong to the criteria of Strömland et al. ${ }^{4}$, four had 3 and eleven had 2 areas.

This study was approved by the Ethics Committee from the Institution.

\section{RESULTS}

All patients $(\mathrm{n}=17)$ were submitted to CNS evaluation through brain CT scan and one, additionally, by MRI. CNS alterations were verified in eight patients (47\%). Diffuse cerebral hypoplasia, dilated lateral cerebral ventricles (asymptomatic hydrocephalus), corpus callosum dysgenesis and frontal hypodensities were the most frequent abnormalities, each one observed in two patients respectively (12\%) (Table 1).

Additional clinical features are showed in Figure and Table 2. In this Table, the patients were divided accord-

Table 1. Central nervous system abnormalities observed among the patients with oculo-auriculo-vertebral spectrum of our sample.

\begin{tabular}{|c|c|c|c|c|c|c|c|c|c|}
\hline \multirow[b]{2}{*}{ CNS abnormalities } & \multicolumn{8}{|c|}{ Patients } & \multirow[b]{2}{*}{ Total } \\
\hline & 1 & 2 & 3 & 4 & 5 & 6 & 7 & 8 & \\
\hline Diffuse cerebral hypoplasia & + & & & + & & & & & 2 \\
\hline Dilated lateral cerebral ventricles or asymptomatic hydrocephalus & & + & + & & & & & & 2 \\
\hline Corpus callosum dysgenesis & & & & & + & & & + & 2 \\
\hline Frontal hypodensities & & & & + & & & & + & 2 \\
\hline Microcephaly & & + & & & & & & & 1 \\
\hline Asymmetric lateral ventricles & & & & & & & + & & 1 \\
\hline Hidrocephalus due to aqueduct of Sylvius stenosis & & & & & & + & & & 1 \\
\hline Corpus callosum lipoma & & & & & + & & & & 1 \\
\hline Absence of septum pellucidum & & & & & + & & & & 1 \\
\hline Diffuse cerebral hypodensity & & + & & & & & & & 1 \\
\hline Hypothalamic hamartoma & & & & & + & & & & 1 \\
\hline
\end{tabular}


Table 2. Clinical features presented by our patients with oculo-auriculo-vertebral spectrum, divided according to the presence or not of CNS abnormalities.

\begin{tabular}{lll} 
& \multicolumn{2}{c}{ CNS alteration } \\
Clinical features & Yes $(\mathrm{N}=8)$ & No $(\mathrm{N}=9)$
\end{tabular}$\quad$ Total $(\mathrm{N}=17)$

\section{Side of commitment}

Right
Left

Bilateral

Neurological

$\begin{array}{ll}\text { Neuropsychomotor delay* } & 5 / 7\end{array}$

Deglutition disorder

Speech delay*

Facial palsy

Hypotonia

Behavioral disorder *

Learning disabilities *

Orofacial

Facial asymmetry

Microretrognathia

Cleft lip / palate

Macrostomia

Hypoplastic tongue

Choanal stenosis

Ophthalmologic **

Epibulbar dermoid

Strabismus

Upper eyelid coloboma

Microphthalmia / anophthalmia

Nystagmus

Dacryostenosis

\section{Auricular}

\section{Microtia}

Preauricular skin tags / pits

External auditory canal agenesis / stenosis

Hearing loss

2
$2 / 7$
2
3
$1 / 3$
$-/ 3$

4

4

$-$

$2 / 7$

2

3

$1 / 3$

$-13$

5

4

3

2

1

1

3

2

2

2

1

$-$
$6 / 8$

6

$4 / 7$

4

2

$1 / 4$

$1 / 4$

5

4

3

2
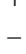

1

-

$-$

$-$

$-$

1
7

9

1

$1 / 15$

8

$6 / 14$

6

5

$2 / 7$

$1 / 7$

10

8

6

4

2

1

4

2

2

2

1

1

13

12

7

5

Skeletal

Hemivertebrae

Hypoplastic vertebrae

Butterfly vertebrae

Spina bifida occulta

Rib alterations

Radial abnormalities

Club foot

6
7
4
2

7
5

3

3

3

$-$

1

2

1

1

1

Others

Congenital heart defect

Short stature

Esophageal atresia / TEF

Renal anomalies

Umbilical / inguinal hernia

Laryngotracheomalacia

Bronchogenic cyst

$\begin{array}{lll}4 & 5 & 9 \\ 2 & 3 & 5 \\ 1 & 2 & 3 \\ 2 & 1 & 3 \\ 2 & 1 & 3 \\ - & 1 & 2 \\ - & 2 & 1\end{array}$

CNS: central nervous system; TEF: tracheoesophageal fistula; *Features evaluated considering the age; **Statistically significant difference between the group with and without CNS alterations in the Fisher exact test. 


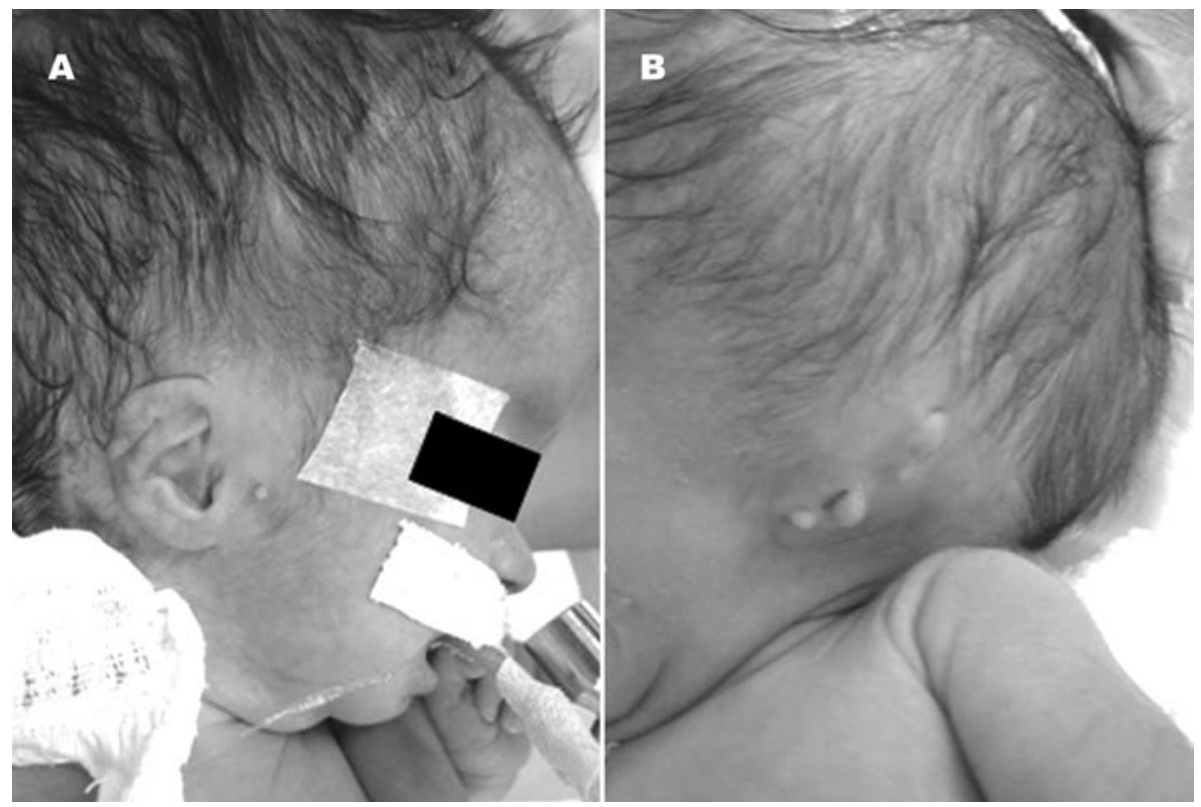

Figure. Patient presenting OAVS and hydrocephalus due to stenosis of the aqueduct of Sylvius. Note especially in the dysplastic right ear with a preauricular skin tag $[\mathrm{A}]$ and in the severe microtia on the left [B].

ing to the presence or not of CNS abnormalities. Presence of ophthalmologic abnormalities was the only clinical association observed, being significantly more frequent among patients with cerebral alterations (63\% versus $11 \%)(\mathrm{p}=0.0498)$.

\section{DISCUSSION}

The frequency of CNS abnormalities found in our study (47\%) was higher than that usually described in the literature, that ranges between 12 and $17 \%^{4,6,7}$. This occurred because, our study only included subjects who had radiological evaluation of the brain. If we considered all the patients with OAVS and normal karyotype diagnosed during the same period in our Service, the frequency of cerebral alterations would pass to $24 \%$ (8 in 34 patients). This data is statistically similar to that described in the literature ${ }^{4,6,7}$. By other hand, when we considered only the patients with CNS radiological evaluation, our rate (47\%) was equal to that found by Engiz et al. ${ }^{8}$ and similar to that of Strömland et al. $(30 \%)^{4}$.

It is known that some alterations, as corpus callosum agenesis/dysgenesis/hypoplasia and lypomas, may not present associated symptoms and could pass imperceptible during the evaluation. Besides, the authors claim attention to the fact that our findings were mainly based on the results of the CT scan evaluation. Overall, the studies reported in the literature do not clearly describe or standardize the form of radiological investigation performed in the patients. Thus, it is possible that some CNS alterations may not have been diagnosed, not only because patients without suspicion of neurological alteration are usually not investigated, but also due to the fact that some abnormalities are detected only through MRI assessment. Probably, these factors lead to an underestimation of the frequency of cerebral anomalies observed among the patients with OAVS.

Cerebral alterations described in patients with OAVS have been showed to be quite variable. This may be a reflex of the pathogenetic heterogeneity observed in OAVS, consisting of a phenotype than a single condition ${ }^{2}$. CNS abnormalities reported include microcephaly, lipomas, hydrocephalus secondary to stenosis of the aqueduct of Sylvius, dilated lateral cerebral ventricles, corpus callosum agenesis/dysgenesis/hypoplasia, cerebellar hypoplasia, Arnold-Chiari malformation and encephaloceles (frontal and, especially, occipital). Cranium bifidum, holoprosencephaly, arhinencephaly, asymmetric lateral cerebral ventricles, absence of septum pellucidum, porencephalic cyst, cortical dysplasia, polymicrogiria, lisencephaly, dermoid cysts, teratomas, intracerebral calcifications, subependimary and choroid plexus cysts, cerebellar vermis hypoplasia/agenesis and Dandy Walker variant have also been observed, but they are rare ${ }^{2,4-8,11-15}$. However, call attention the presence, in our sample, of three cases with cerebral hypodensities (two of them involving the frontal region and the other generalized). These are uncommon features in OAVS. Besides, we did not find reports in the literature of patients presenting a hypothalamic hamartoma.

In our sample, we verified a predominance of male 
subjects, in agreement with the literature. The association between CNS and ophthalmologic abnormalities was previously described by other authors ${ }^{5,6}$, and seems to be related with the fact that these structures belong to the same embryonic development field ${ }^{6}$. By other hand, we did not find difference between the groups with and without cerebral alterations in relation to the side of commitment, neither to the presence of orofacial clefts, vertebral anomalies and neurological alterations, as neuropsychomotor delay and behavioral disorders ${ }^{2,5,6}$.

Thus, CNS alterations are frequent among patients with OAVS, occuring especially among carriers of ophthalmologic abnormalities. Neurological alterations as neuropsychomotor delay, hypotonia and learning disabilities are common in subjects without detectable CNS abnormalities. However, it is important to consider the possible limitations of the radiological evaluation adopted, where some abnormalities can pass undetectable. The absence of cerebral alterations did not exclude the possible development of neurological symptoms. Therefore, the careful investigation is extremely important for the proper management of subjects with OAVS.

\section{REFERENCES}

1. Online Mendelian Inheritance in Man, OMIM (TM). McKusick-Nathans Institute for Genetic Medicine, John Hopkins University (Baltimore, MD) and National Center for Biotechnology Information, National Library of Medicine (Baltimore, MD). Available at: http://www.ncbi.nlm.nih.gov/omim. Accessed $09 / 12 / 2009$
2. Cohen MM Jr, Rollinck BR, Kaye Cl. Oculoauriculovertebral spectrum: an updated critique. Cleft Palate J 1989;26:276-286.

3. Castori M, Brancati F, Rinaldi R, et al. Antenatal presentation of the oculo-auriculo-vertebral spectrum (OAVS). Am J Med Genet 2006;140:1573-1579.

4. Strömland K, Miller M, Sjögreen L, Johansson M, Joelsson BM E, Billstedt E. Oculo-auriculo-vertebral spectrum: associated anomalies, functional deficits and possible developmental risk factors. Am J Med Genet 2007;143:1317-1325.

5. Schrander-Stumpel CT, de Die-Smulders CE, Hennekam RC, et al. Oculoauriculovertebral spectrum and cerebral anomalies. J Med Genet 1992;29:326-331.

6. Tasse C, Böhringer S, Fischer S, et al. Oculo-auriculo-vertebral spectrum (OAVS): clinical evaluation and severity scoring of 53 patients and proposal for a new classification. Eur J Med Genet 2005;48:397-411.

7. Touliatou V, Fryssira H, Mavrou A, Kanavakis E, Kitsiou-Tzeli S. Clinical manifestations in 17 Greek patients with Goldenhar syndrome. Genet Couns 2006; 17:359-370

8. Engyz O, Balel S, Unsal M, Ozer S, Oguz KK, Aktas D. 31 cases with oculoauriculovertebral dysplasia (Goldenhar syndrome): clinical, neuroradiologic, audiologic and cytogenetic findings. Genet Couns 2007;18:277-288.

9. Normal Standars. In: Jones KL (Ed). Smith's recognizable patterns of human malformation. Philadelphia: Elsevier Saunders, 2006:835-863.

10. Rollnick BR, Kaye Cl, Nagatoshi K, Hauck W, Martin AO. Oculoauriculovertebral dysplasia and variants: phenotypic characteristic of 294 patients. Am J Med Genet 1987;26:361-375.

11. Wilson GN. Cranial defects in the Goldenhar association. Am J Med Genet 1983;14:569-578.

12. Pauli RM, Jung JH, McPherson EW. Goldenhar association and cranial defects. Am J Med Genet 1983;15:177-179.

13. Aleksic S, Budzilovich G, Greco MA, Epstein F, Feigin I, Pearson J. Encephalocele (cerebellocele) in the Goldenhar-Gorlin syndrome. Eur J Pediatr 1983; 140:137-138.

14. Aleksic S, Budzilovich G, Greco MA, et al. Intracranial lipomas, hydrocephalus and other CNS anomalies in oculoauriculovertebral dysplasia (Goldenhar-Gorlin syndrome). Childs Brain 1984;11:285-297.

15. Digilio MC, Calzolari F, Capolino R, et al. Congenital heart defects in patients with oculo-auriculo-vertebral spectrum (Goldenhar syndrome). Am J Med Genet 2008;146:1815-1819. 